\title{
Tracheal mucosal flap: A rare cause of delayed onset postextubation stridor
}

\author{
Shameela $\mathbf{K}^{1^{*}}$, Anitha Kumari $\mathbf{A M}^{2}$ \\ ${ }^{1}$ Resident, ${ }^{2}$ ENT Consultant, Manipal Hospitals, Bangalore, Karnataka, India \\ Corresponding Author: Shameela K \\ Email: shameela.k.alavi@gmail.com
}

\begin{abstract}
Tracheal intubation is a commonly done procedure for myriad conditions, mainly in emergency rooms, operation theatres and ICUs. It is associated with several complications especially when performed under emergency conditions. Tracheal mucosal tear is a rare entity which is almost always undiagnosed. At times it leads to mucosal flap which is a cause of delayed onset respiratory distress following extubation. Misdiagnosis of this condition can prove fatal. One such case of tracheal mucosal flap is reported here highlighting the typical clinical features. A detailed study of the pathological process also follows. Awareness of this entity among the medical fraternity handling airway of critically ill patients is of utmost value.
\end{abstract}

Keywords: Postextubation stridor, Positional stridor, Pseudomembrane, Mucosal flap.

\section{Introduction}

It is not uncommon to encounter stridor soon after extubation of a patient who has been intubated with an endotracheal tube for mechanically assisted ventilation, most commonly due to inflammation or ischaemia of the laryngotracheal mucosa. ${ }^{1-3}$

Occasionally, ulceration occurs, especially in the subglottis and most commonly in the region of the cervi-cotrachea $^{1,2}$ (due to traumatic intubation or endotracheal cuff pressure necrosis, now rare due to the advent of the high-volume, low-pressure cuff). The resultant granulation tissue and scar formation can also cause stridor if the tracheal lumen is sufficiently compromised. These patients may be quite well in the immediate post-extubation period but may gradually develop stridor due to progressive thickening of the scar tissue.

Tracheal stenosis is generally due to circumferential (intra-luminal) granulation tissue thickening and scarring, with the onset of stridor and respiratory embarrassment when suffi-cient narrowing of the lumen has occurred. Stridor due to true tracheal stenosis does not vary much in its severity or audibility with changes in position (i.e. whether the patient is supine, prone or upright), because it is due to a ring of tissue formed within the tracheal lumen.

However, if the stridor is due to a tracheal flap on the pos-terior wall, supine positioning will cause the flap to fall back, partially relieving the patient's respiratory distress, while prone positioning will cause the flap to fall forward, worsen-ing respiratory distress. In the upright posture, however, the Outcome of ICU stay is improving nowadays. However it is not uncommon to encounter problems after extubation following assisted mechanical ventilation. Incidence of postextubation stridor is $12 \%$.

Common causes of immediate postextubation respiratory distress include laryngospasm, laryngeal edema and cord injury. All ICUs have set protocols prior to extubation and postextubation to tackle these. Late onset distress can be due to tracheal stenosis, granulation tissue. Tracheal pseudomembrane and mucosal flap are two causes added to this.

Risk factors of postextubation stridor include excessive airway manipulation, traumatic intubation, prolonged intubation attempt (>10 min), oroendotracheal intubation, larger tubes, intubation > 36 hours, agitation while intubated, high cuff pressures, recurrent intubations, female,short neck, known airway pathology), children and small height: internal diameter ETT ratio. Other probable risk factors are prolonged corticosteroid use, tracheomalacia, malpositioning of the endotracheal tube, use of the stylet to guide the endotracheal tube between the vocal folds, and excessive coughing. ${ }^{1-4}$

Knowledge of the rare causes is of utmost importance as appropriate management will give excellent results, making the entire effort of the ICU team in treating the primary pathology fruitful.

\section{Case Report}

57 year old lady came to ER with respiratory distress and drowsinessand was diagnosed to have respiratory failure secondary to pneumonia. Patient was intubated with $7.5 \mathrm{~mm}$ cuffed endotracheal tube. Intubation was uneventful. She got admitted in MICU. She was continued on controlled mechanical ventilation and given medications for the primary pathology. Her breathing mechanism improved in 48 hours and was 
extubated. After five days of extubation, she developed sudden onset of breathing difficulty and stridor. Patient was more symptomatic in supine position and better on sitting. Patient was started on systemic steroids and nebulization. Since symptoms were not improving, airway evaluation was done.

Flexible bronchoscopy under LA revealed grade I subglottic stenosis and a mucosal flap starting four rings below the stenosis extending inferiorly for 2-3 cms obstructing the visualization of trachea below. CTthorax which was taken two days after extubation showed normal trachea. So, Dynamic CT neck was taken and showed circumferential wall thickening extending from C7-T2 vertebral level for a length of $3.3 \mathrm{~cm}$ causing 50-60\% narrowing [Fig. 1,2].

Rigid bronchoscopy and removal of the flap done under GA.A mucosal flap $3 \mathrm{~cm}$ with longitudinal attachment on right side of trachea at the chondromembranous junction was removed. Raw area present over the attachment of flap. Rest of trachea was normal. [Fig. 3] Histopathology showed inflammatory etiology. Drastic improvement of the symptoms was noted. She was discharged after $24 \mathrm{hrs}$.

One week later, Patient was totally asymptomatic and repeat flexible scopy showed no residual lesion and completely healed trachea.

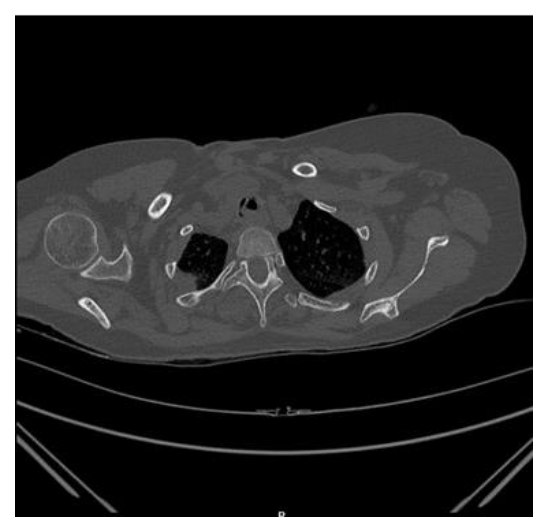

Fig. 1: Axial_cut

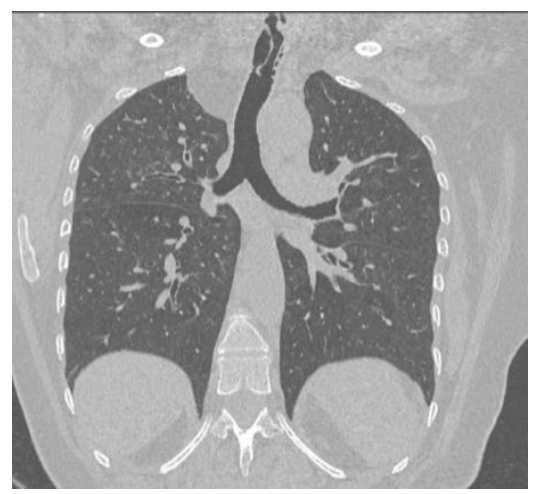

Fig. 2: Coronal_cut

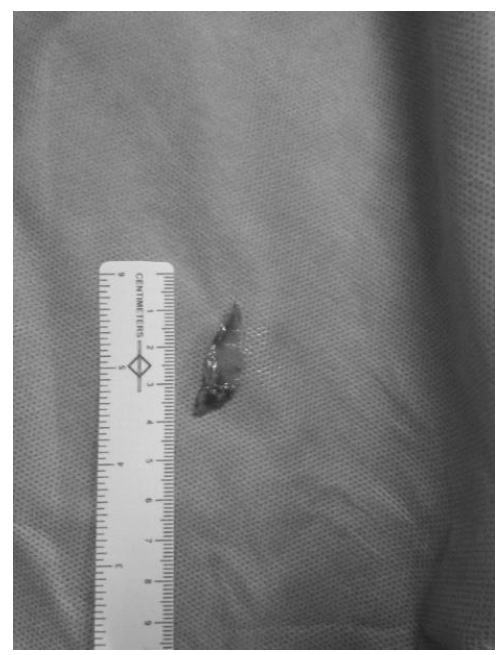

Fig. 3: Mucosal_flap

\section{Discussion}

The exact etiopathogenesis of tracheal flap remains unknown. Various hypotheses have been postulated. The subglottic area is the narrowest part of the larynx that is completely surrounded by the cricoid cartilage that forms a rigid circle. Due to this, the subglottic mucosa is vulnerable to injury that may occur after intubation. Initial injury results in accumulation of the desquamated epithelial cells that subsequently form the subglottic membrane. This theory is supported by the fact that the most common location of the tracheal pseudomembrane is the subglottic region. ${ }^{[5]}$ However in a few other cases, the membrane is located in the mid-trachea, distal trachea, or the entire length of trachea. Another theory suggests the membrane to be the first step in the development of tracheal stenosis resulting from ischemic necrosis of tracheal mucosa and submucosa due to inflated endotracheal cuff. ${ }^{6}$ Aspiration of gastric contents leading to caustic injury has also been proposed as a contributing factor. It is likely that a combination of these factors results in the formation of tracheal mucosal flap after initial trauma to the tracheal mucosa followed by an aberrant healing process. Another postulation for long tracheal flaps is progressive extension of mucosal elevation via the unhealed mucosal tear during each inspiratory effort post extubation as in dissection of blood vessels. ${ }^{7}$

The onset of respiratory distress varies, ranging from first hour to 14 days after extubation. The symptoms are cough, hoarseness of voice, stridor and respiratory distress. ${ }^{5}$ The key to suspicion of flap is change in stridor with position and delay in onset of symptoms.

In the stridor due to a tracheal flap on the posterior wall, supine positioning will cause the flap to fall back, partially relieving the patient's respiratory 
distress, while prone positioning will cause the flap to fall forward, worsening respiratory distress. In the upright posture, however, the process of respiration (especially when forceful) will cause the flap to act as a one-way valve, allowing expired air to pass up and out easily but trapping inspired air and thus narrowing the tracheal lumen during inspiration. ${ }^{7}$

One has to rule out conditions like laryngeal spasm, cord palsy, heart failure, and retention of tracheobronchial secretions, granulation and stenosis.

The presence of tracheal flap is confirmed by direct visualization of the membrane during flexible bronchoscopy. However, flexible bronchoscopy cannot be performed in patients who have severe respiratory distress or respiratory failure. In such cases, computed tomography of the neck and the thorax can provide clues to the cause of the respiratory symptoms.

Treatment involves confirmation by flexible bronchoscopy and removal of the membrane using rigid or flexible bronchoscopy. ${ }^{8-10}$ Dynamic CT can confirm its presence.

The safest modality of treatment is rigid bronchoscopy. Rigid bronchoscopy offers several advantages over flexible bronchoscopy. Rigid bronchoscopy allows ventilation during diagnosis and removal of the flap. This is important because tracheal flap causes significant luminal narrowing and the introduction of the flexible bronchoscope may further obstruct the airway. Also in a tachypneic patient, flexiblebronchoscopy may worsen the dynamic tracheal obstruction due to a floppy membrane. ${ }^{8-10}$

If the tracheal membrane is large, thick and adherent, removal and manipulation may not be possible with the flexible bronchoscopy.

In case of respiratory compromise due to very large flaps and in those conditions requiring assisted ventilation, patient may require reintubation or tracheostomy at a level lower to the flap. One should be aware that blind intubation can cause total airway obstruction due to dislodgement of the flap. Hence, intubation should be done under endoscopic visualization so that the flap is repositioned back so that it heals.

In conclusion, tracheal mucosal flap should be considered in cases of delayed onset post extubation stridor since misdiagnosis can prove fatal and early diagnosis is crucial.

\section{Source of funding}

None.

\section{Conflict of interest}

None.

\section{References}

1. Zias N, Chroneou A, Tabba MK, Gonzalez AV, Gray AW, Lamb CR et al. Post tracheostomy and post intubation tracheal stenosis:report of 31 cases and review of the literature. BMC Pulmonary Med 2008;8:18

2. Cardillo G, Carbone L, Carleo F, Batzella S, Jacono RD, Lucantoni G. Tracheal lacerations after endotracheal intubation: a proposed morphological classification to guide non-surgical treatment. Eur J Cardiothorac Surg 2010;37:581-7.

3. Beebe DS. Complications of tracheal intubation. Semin Anesth, Perioper Med Pain 2001;20:166-72.

4. Miñambres E, Burón J, Ballesteros MA. Tracheal rupture after endotracheal intubation: a literature systematic review. Eur J Cardiothorac Surg 2009;35:1056-62.

5. Etsten B, Mahler D. Subglottic membrane; a complication of endo-tracheal intubation. $N$ Engl J Med 1951;245(25):959-60.

6. Desle'e G, Brichet A, Lebuffe G, Copin MC, Ramon P, Marquette $\mathrm{CH}$. Obstructive fibrinous tracheal pseudomembrane: a potentiallyfatal complication of tracheal intubation. Am J Respir Crit Care Med 2000;162(3 Pt 1):1169-71.

7. Tan K 1, Chong AW, Amin MA, Raman R.Iatrogenic tracheal flap mimicking tracheal stenosis with resultant stridor. J Laryngology Otol 2012;126:751-5.

8. Lins M, Dobbeleir I, Germonpre' P, Waelput W, Pauwels $\mathrm{P}$, Jorens PG et al. Postextubation obstructive pseudomembranes: a case series andreview of a rare complication after endotracheal intubation. Lung 2011;189(1):81-6.

9. Soong WJ, Jeng MJ, Lee YS, Tsao PC, Yang CF, Soong YH. Pediatric obstructive fibrinous tracheal pseudomembrane: characteristics and management with flexible bronchoscopy. Int J Pediatr Oto-rhinolaryngol 2011;75(8):1005-1009.

10. Talwar A, Patel N, Omonuwa K, Lisker G. Postintubation obstructive pseudomembrane. J Bronchology Interv Pulmonol 2008;15(2):110-2.

How to cite: Shameela K, Anitha Kumari AM. Tracheal mucosal flap: A rare cause of delayed onset postextubation stridor. IP J Otorhinolaryngol Allied Sci 2020;3(1):26-8. 